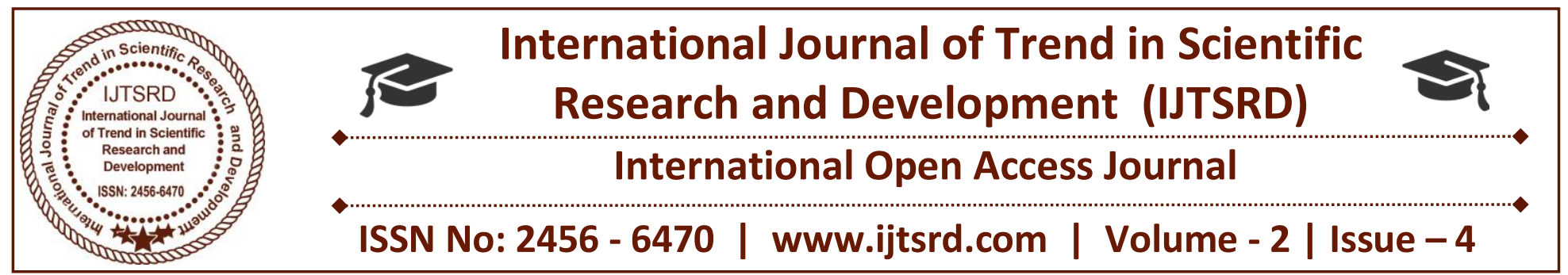

\title{
Analysis of Climate Change for Sustainable Farming
}

\author{
Qulsum Umer H Shaikh, Anisha Raniwala
}

School of Engineering and Technology, Jain University, Bengaluru, Karnataka, India

\begin{abstract}
Environmental change and agribusiness are interrelated procedures, both of which occur on a worldwide scale. Environmental change influences farming in various fields, incorporating through changes in normal temperatures, precipitation, and atmosphere extremes (e.g., warm waves); changes in desease and pests ; changes in air carbon dioxide and ground-level ozone fixations; changes in the nutritious nature of a few sustenance and changes in ocean level. All through the 21 st century, India is anticipated to encounter warming above worldwide level. India will likewise start to encounter more occasional variety in temperature with more warming in the winters than summers. Life span of warmth waves crosswise over India has reached out lately with hotter night temperatures and more sizzling days, and this pattern is relied upon to proceed. As of late, the harvest recreation models have been utilized broadly to consider the effect of environmental change on agrarian generation and nourishment security. The yield gave by the reproduction models can be utilized to settle on suitable product administration choices and to give ranchers and others elective choices for their cultivating framework. It is normal that in the coming a long time with the expanded utilization of PCs, the utilization of reenactment models by agriculturists and experts and also approach and leaders will increment. Proposed model will help agriculturists in choosing the yield which they can create without depending on chemicals and diverse cultivating strategies. The present and changing conditions will be sufficient for the product compose proposed by the model.
\end{abstract}

KEYWORDS: Sustainable farming, agriculture, big data, data analysis, climate change, crop prediction

\section{INTRODUCTION}

Global climate change is an adjustment in the long haul climate designs that describe the locales of the world. The expression "climate" alludes to the transient (day by day) changes in temperature, wind, as well as precipitation of a locale. Over the long haul, the climatic change could influence farming in a few routes, for example, amount and nature of harvests as far as efficiency, development rates, photosynthesis and transpiration rates, dampness accessibility and so on. Environmental change is probably going to straightforwardly affect sustenance creation over the globe. Increment in the mean regular temperature can lessen the length of numerous products and thus diminish the yield. In zones where temperatures are as of now near the physiological maxima for crops, warming will affect yields all the more promptly. The outcomes of agribusiness' commitment to environmental change, and of environmental change's negative effect on farming, are serious which is anticipated to greatly affect sustenance creation and may debilitate the nourishment security and thus, require unique agrarian measures to battle with.

The objective of practical farming is to meet society's nourishment and material needs in the present without bargaining the capacity of future ages to address their own particular issues. Professionals of supportable agribusiness look to coordinate three primary destinations into their work: a solid situation, monetary productivity, and social and financial value. Each individual engaged with the sustenance framework - cultivators, nourishment processors, merchants, retailers, buyers, and waste chiefs - can assume a part in guaranteeing an economical rural framework.

There are numerous practices ordinarily utilized by individuals working in supportable farming and 
manageable nourishment frameworks. Producers may utilize techniques to advance soil wellbeing, limit water utilize, and bring down contamination levels on the ranch. Customers and retailers worried about supportability can search for "values-based" nourishments that are developed utilizing strategies advancing farm worker prosperity, that are ecologically well disposed, or that fortify the neighborhood economy. Also, specialists in supportable horticulture frequently cross disciplinary lines with their work: consolidating science, financial matters, designing, science, group improvement, and numerous others. Nonetheless, manageable farming is in excess of an accumulation of practices. It is additionally procedure of transaction: a push and draw between the occasionally contending interests of an individual rancher or of individuals in a group as they work to take care of complex issues about how we develop our nourishment and fiber.

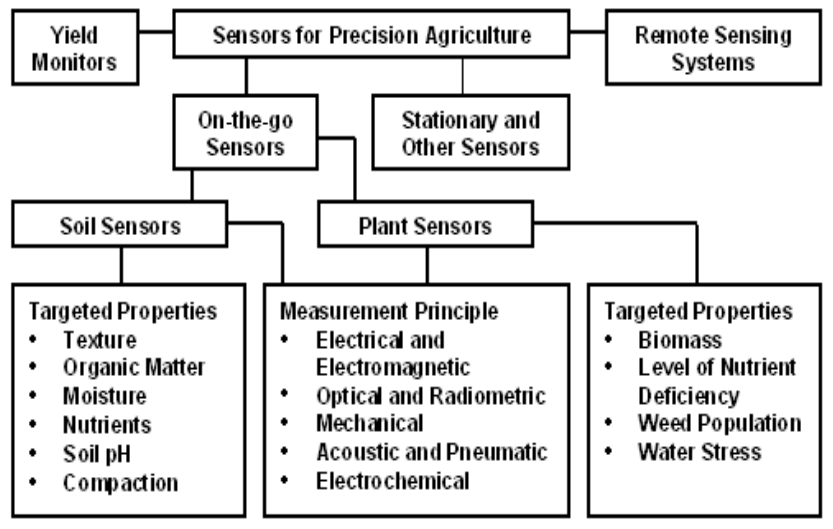

Figure 1: Sensors for Precision Agriculture.

Methods of sustainable agriculture include:

\section{Crop Rotation}

Crop rotation is a standout amongst the most intense procedures of maintainable agribusiness. Its motivation is to maintain a strategic distance from the results that accompany planting similar yields in a similar soil for quite a long time in succession. It helps handle bother issues, the same number of nuisances lean toward particular harvests.

\section{Cover Crops}

Numerous agriculturists have crops planted in a field constantly and never abandon it desolate, this can cause unintended results. By planting spread harvests, for example, clover or oats, the rancher can accomplish his objectives of anticipating soil disintegration, stifling the development of weeds, and upgrading the nature of the dirt. The utilization of cover edits likewise diminishes the requirement for chemicals, for example, manures.

\section{Soil Enrichment}

Soil is a focal part of agrarian biological systems. Solid soil is brimming with life, which can regularly be murdered by the abuse of pesticides. Great soils can build yields and in addition making more vigorous harvests.

\section{Natural Pest Predators}

Keeping in mind the end goal to keep up powerful control over nuisances, it is essential to see the homestead as an environment rather than an industrial facility. For instance, numerous feathered creatures and different creatures are in actuality regular predators of agrarian nuisances.

Bio concentrated Integrated Pest Management: Integrated vermin administration (IPM). This is an approach, which truly depends on organic instead of synthetic techniques.

Benefits of sustainable farming are:

\section{Contributes to Environmental Conservation:}

Nature assumes a colossal part in satisfying our essential needs to support life. Thusly, it is our obligation to take care of the earth with the goal that future ages are not denied of their needs.

Public Health Safety: Sustainable horticulture keeps away from dangerous pesticides and manures. Accordingly, agriculturists can deliver natural products, vegetables and different yields that are more secure for buyers, specialists, and encompassing groups.

Prevents Pollution: Sustainable agribusiness implies that any waste a homestead produces stays inside the ranches environment. Along these lines the waste can't cause contamination.

Reduction in Cost: The utilization of practical agribusiness decreases the requirement for petroleum derivatives, bringing about huge cost funds regarding obtaining and also transporting them. This thus diminishes the general costs engaged with cultivating.

Biodiversity: Sustainable homesteads create a wide assortment of plants and creatures bringing about biodiversity. Amid edit revolution, plants are regularly turned and this outcomes in soil advancement, avoidance of maladies, and nuisance episodes. 
Beneficial to Animals: Sustainable agribusiness brings about creatures being better looked after, and approached altruistically and with deference. The normal practices of every single living creature, including touching or pecking, are provided food for. Thus they create normally. Manageable agriculturists and farmers execute domesticated animals cultivation hones that secure creatures' wellbeing.

Economically Beneficial for Farmers: In trade for connecting with supportable cultivating strategies, agriculturists get a reasonable wage for their create. This incredibly diminishes their dependence on government sponsorships and fortifies country groups. Natural homesteads ordinarily require $2 \frac{1}{2}$ times less work than manufacturing plant cultivates yet return 10 times the benefit.

Social Equality: Practicing practical horticulture methods additionally benefits specialists as they are offered a more aggressive compensation and in addition benefits. They additionally work in others conscious and reasonable working conditions, which incorporate a sheltered workplace, nourishment, and satisfactory living conditions.

Beneficial for Environment: Sustainable farming diminishes the requirement for utilization of nonsustainable power source assets and subsequently benefits the environment .This significantly lessens their dependence on government sponsorships and reinforces country groups.

Ways in which big data analytics can help agriculture industry are:

\section{Accurate crop predictions}

Holding up to perceive how the yields turn out has been driving men to drink since... well, since we've had liquor to drink. We've had a go at everything from the rain move to grave petition, however trim expectations during the time have been definitely not precise, up to this point.

By utilizing modern PC calculations to examine decades and at some point a very long time of climate and harvest information, the present agriculturists can anticipate trim yields with stunning exactness, before planting a solitary seed. The knowledge gave by information examination enables ranchers to begin and gather their harvests at the ideal time, which expands trim yields and limits pressure.

\section{Stronger seeds and less hunger}

An expanding worldwide populace joined with rising temperatures has prompted a monstrous starvation in Africa which has left 20 million individuals in danger of starvation. Philanthropic gatherings over the globe have equipped to offer help anyway they can, yet the arrangement may lie in huge information.

Physicists and horticultural researchers have been dissecting plant information for quite a long time in the expectations of creating crops that can develop in any condition. We can develop plants speedier, taller, and heartier than any time in recent memory - and starting keep going March, clearly on Mars too. Synthetically built seeds composed utilizing huge information may seem like an awful thing at first glance and the news typically depicts it that way. In any case, seeds made utilizing information investigation could put a conclusion to world yearning.

\section{Automated agriculture}

Automated cultivating or exactness horticulture is just the same old thing new. For quite a long time we've been utilizing diverse frameworks to mechanize and monitor however many agrarian procedures as could be expected under the circumstances. From numerous points of view, information investigation was what isolated business agriculturists from the pack some time before huge information was even a term.

Information examination is tied in with finding the moment blemishes in a framework and redressing them, sadly, the human component is very frequently that modest imperfection. Enormous information has us well on our approach to farmerless ranches.

\section{Environmental awareness}

Sparing the earth sounds incredible from a human viewpoint, yet the farming business is only that, an industry, a business, and all business choices live beyond words the primary concern. Huge information is demonstrating organizations in the horticulture business that not exclusively would you be able to secure nature without expanding costs, you can decrease them. It's not only the assembling business that is rolling out improvements to lessen their ecological effect, ranchers and agribusiness organizations have been driving the way.

\section{PROBLEM STATEMENT}

All of us are dependent on food, which comes from environment. Majority of India is somehow involved in the agriculture related activities. They are bread 
earning and providing work. Farming is the top most of profession of Indians yet farmers are suffering due a lot of reasons. One of the reasons is climate change. Climate change is happening rapidly in the last few years. Global warming, has led the earth to warm up and decrease in the rainfall. Soil conditions are also being degraded by using pesticides and other chemicals to increase the yield of crop. Agriculture largely depends on whether condition, rainfall and accurate water level that help the farmer to plan their crop according to current scenario. Therefore, big data with map reduce help better weather forecasting. The technologies involved with such predictive system are yet not available to Indian farmers but government is taking some steps towards it.

A system which can take into consideration factors such as: soil quality, water level, temperature, rainfall, wind etc. and predict the type of crop which can be grown in that particular area with the given factors is demanded. With the help of big data tools, the crop to be planted and cultivated can be predicted. The proposed system aids the same. Other technique is where data mining is used for analyzing the biotic and abiotic factors related to agriculture. The common problem among Indian farmers is that they don't choose the right crop to cultivate and later face problems. These kind of precision systems can help them grow the right crop.

\section{THE EXISTING SYSTEM}

In Existing system,Techniques to predict the crop yield and methodologies to take advantage of massive data related to climate require profound understanding. In the age of information, these objectives could be realized via Big Data applications. Ch. Chandrasekhar, Ch.Sekhar [1] proposed a system that helps farmers to grow suitable crops based on the climatic conditions. The process happens in different stages like information gathering, data analysis, and alert system and visualization modules. $\mathrm{K}$. Ravisankar, K. Sidhardha, PrabadeviB[2] proposed use of the Map reduction Techniques of Big Data Analysis which is advantageous over the data mining techniques.

Other technique is where data mining is used for analyzing the biotic and abiotic factors related to agriculture. The common problem among indian farmers is that they don't choose the right crop to cultivate and later face problems. These kinds of precision systems can help them grow the right crop.
Techniques like CHAID, Random tree, K-nearest neighbor are being used to recommend a crop for a site in specific parameters with high accuracy and efficiency that will be further used for better crop cultivation [3].

In order to deduct noise the raw data was taken further proceeding to imputation methods and then refinement of respective data. Next process was to subject the data to Feature selection which will then convert the data into the preferable format. Later undergoes through various Regression techniques and hence the development of predictive models. These results of the analysis will be compared and tested [4]. Regression analysis is responsible for comparison that effects measured variables on dissimilar scales, such as a effects on the number of promotional activities and over the price variations. These results make great advantage to data analysts or data scientists or market researchers to estimate and eliminate the variables group which are useful for the development of models for prediction. Many regression techniques works on making predictions [5]. These techniques are most of the times derived through three metrics i.e. the pattern of regression line drawn, the type of dependent variables and a number of independent variables.

K-Nearest Neighbor: For both grouping and relapse, K-Nearest Neighbor Algorithm can be favored. It is a non-complex calculation which helps in putting away of the considerable number of cases and classifications new cases in view of past measure. The example set is then characterized relying upon the "closeness" that separation is estimated, for example, Euclidean separation or Manhattan remove.

Naive Bayes: It works in view of applying Bayes' hypothesis with solid guileless freedom suspicions, and is a straightforward probabilistic classifier which. Guileless Bayes is a strategy for creating classifier models that doles out particular class names to issue objects which are indicated as vectors of highlight esteems, from where class names are taken from given limited set. It's anything but a solitary calculation for speaking to such classifiers, yet a group of calculations relying upon regular standard .All credulous Bayes classifiers makes a supposition that the estimation of a specific component isn't reliant of the estimation of some other element. Numerous relapse methods chips away at making expectations. These systems are the vast majority of the circumstances inferred through three measurements 
i.e. the example of relapse line drawn, the kind of ward factors, various autonomous factors.

\section{A. Limitation of The Present System}

Many techniques have been proposed with improved technologies. But every system has some limitations which can be improved such as:

1. The local farmers are mostly illiterate or merely know the local language properly. So the technology should be made available to them in the local language.

2. The technology proposed is not always cheap. The government or the agencies should take some action to make it available at cheaper cost.

3. There are many reasons such as language and distance because of which the data is not being shared across the people of the same country.

4. Different types of sensors, satellite images etc. have to be used to take the input of the data.

5. The climate change is affecting the data collected before and that is being collected to a greater extent. As the climate is changing at a faster speed, it is becoming difficult to predict the rainfall or the temperature of a place.

6. With respect to the prediction of time, series model the accuracy is short termed. As times increasing, the predicted error will gradually increase.

7. Sustainable farming is not being achieved even after all these efforts.

\section{THE PROPOSED SYSTEM}

The important factors that affect agriculture and make an impact for sustainable farming are

\section{Temperature}

Many plants can't be grown, if the temperature falls below the threshold that is $6^{\circ} \mathrm{C}$ the soil is hardened for five consecutive months. As a result various locales are forbidden for trim improvement.

\section{The developing seasons}

The measure of days between the last ice of the spring and the first of the pre-winter. Unmistakable yields require contrasting lengths of making season. Cotton needs 200 days so couldn't make due in a British situation. Oat crops are delivered in the South-east of Britain as this is the region well while in travel to meet the basic making season. The shorter the required making season the further north that yield can be created. Oats can be found in Northern parts of the UK since they have a short making season.

\section{Elevation}

This impacts temperature so it in like manner impacts developing. In the Alps for example you will find dairy developing in valley bottoms and coniferous officer benefit moreover up.At the moment that temperatures are dependably high with satisfactory precipitation exceptional yield items, for instance, rise can be created. These have the extra good position of conveying up to three items consistently.

\section{Precipitation}

Water is obviously a key factor in plant change. The more recognizable the conventional temperature the more basic the measure of water required for plant progression. Occasional collection is key as various things require water at various conditions. Espresso for instance should have a time of dry season as of now and amidst get while maize would profit by overwhelming precipitation in a practically identical period. An agriculturist is along these lines chasing down precipitation dependable quality with the target that he can pick the most fitting harvest for the zone.

Rice is the basic harvest in the tropics since it requires essential measures of water, is an excellent yield trim and has great sustaining worth. With the advancement of reliably high temperatures it can comparatively make a few gathers every year. In the Mediterranean thing progression is affected by the mid year dry season paying little heed to high yearly precipitation.

The precipitation is high in winter months however assault rates are similarly low. In summer temperatures are high, reassuring high rates of evapotranspiration and thus to an extraordinary degree dry soil and a low water table. There is a dirt saturation lack. These conditions are not valuable for plant progression.

\section{Wind}

Wind can dangerously influence crops. At its most genuine an ocean whirlwind canss physically pummel countless of place that is known for farmland. Less outrageous yet what's more ruinous are the breezes that dry soils so diminishing sogginess and growing the potential for soil breaking down.

As change in atmosphere is influencing the gathered information previously and that is being gathered to a more prominent degree. At a speedier speed the atmosphere is transforming, it has turned out to be 
more troublesome keeping in mind the end goal to anticipate the temperature or the precipitation of a place. So as to tackle these issues we are utilization of a few sensors. One of them is Satellite remote sensor.

Satellite remote sensor has contributed real advances in better knowing the atmosphere framework and its progressions, by evaluating forms and spatial-worldly conditions of the encompassing or air , land, ocean and seas. In this Report, we feature some essential revelations with respect to the atmosphere framework that have not been recognized by any atmosphere models and any ordinary observations for illustration, the spatial example of ocean level ascent and the cooling impacts of expanded stratospheric pressurized canned products.

New records are made possible by the not paralleling worldwide scale and fine-scale spatial scope of satellite perceptions. By and by, the negligible span of perception arrangement and their not being assurances still stance challenges for catching the powerful long haul patterns. So here we call attention to the prerequisite for future work and future frameworks to make best utilization of remote detecting in environmental change thinks about. Prior Conventional land-based perceptions were utilized to commonly gathered at settled interims with constrained spatial scope, where as Satellite remote sensor makes it workable for consistent checking on the worldwide scale.

More exact soil properties are expected to make a fruitful execution on location particular administration choices. Lacking thickness of tests and the more cost of customary soil tests and examination have been significant restricting components. Vehicle-based soil sensors speak to an elective that could both improve the quality and decrease the speculations made on soil maps.

At the point when grown further, in a hurry soil sensors might be valuable for either ongoing or outline control of rural information sources. To date, just frameworks that guide electromagnetic soil properties are accessible commercially. Earlier Conventional land-based perceptions were utilized to normally gathered at settled interims with restricted spatial scope, where as Satellite remote sensor makes it feasible for ceaseless observing on the worldwide scale.

\section{A. Algorithm}

Input about different factors as mention above that effect production of crop and taken through sensor and statistical data the input data is then compared with the data that has been collected over the years. And with the predicted climate change. After the comparison the system gives choices of few crop which can be produced with the present climatic condition and factors without much use of pesticide and exploitation of nature resulting in sustainable farming.

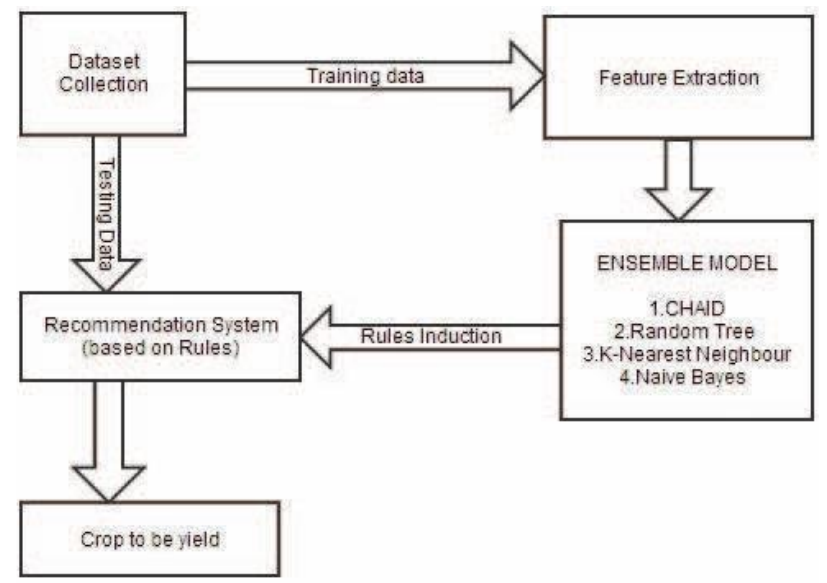

Figure 2: Proposed system

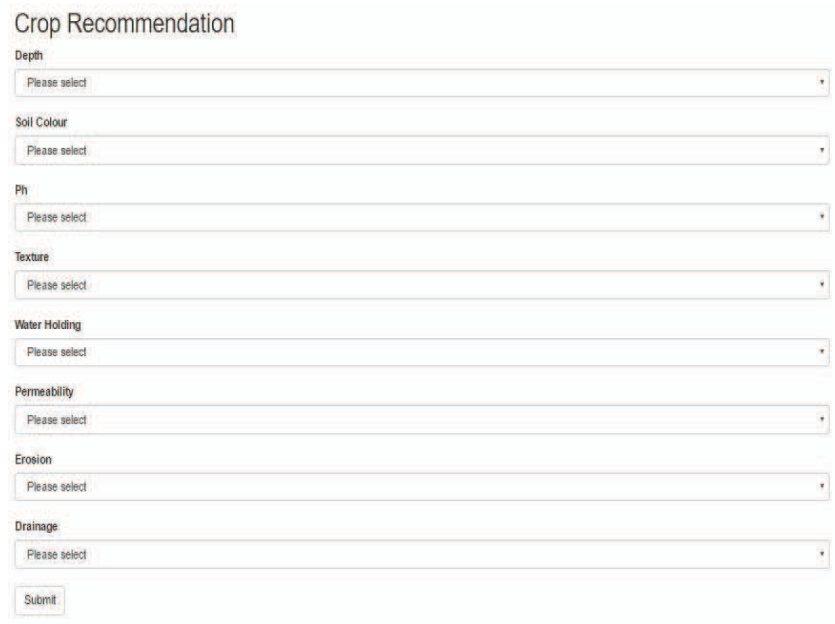

Figure 3

\section{CONCLUSION}

In the present article, an application is proposed that can be used to know which type of crop can be produced with minimal use of chemicals, water etc. on a particular site without exploiting the soil and the environment which will result in the sustainable farming.

Basically, the data from the past is collected and with the help of big data analysis tool the prediction is made.It gives the farmers a fair idea for planting the best crop based on the weather alerts that gives 
information about the climatic conditions. Therefore, farmers can choose the best crop based on the prevailing climatic conditions. This will reduce the human labor, time taken, money involved and produce a better quality crop.

\section{References}

[1] S.Pudumalar, E.Ramanujam,R.HarineRajashree, C.Kavya, T.Kiruthika, J.Nisha., "Crop recommendation system for precision agriculture", IEEE International conference on advanced computing: 2016

[2] Ch.Chandra Sekhar,Ch.Sekhar,'Productivity Improvement in Agriculture sector using Big Data Tools" IEEE ,978-1-5090-6399-4/17,2017

[3] PaveeSiriruk, PhornpanThongpang, "An Analysis of Cassava Price Transmission in Thailand",9781-5090-6775-6/17@2017 IEEE

[4] Mukeshkumar,Prof.Mayuranagar,"Big Data analytics in agriculture and distribution channel",Proceedings of the IEEE 2017 International Conference on Computing Methodologies and Communication(ICCMC),978-1-5090-4890-8/17.

[5] HualinXie and Bohao Wang, "An Empirical Analysis of the Impact of Agricultural Product Price Fluctuations on China's Grain Yield", Published: 29 May 2017.

[6] Bharath G, Anala M R , "Big Data Analytics in Precision Agriculture: A Survey",International Journal of Research and Scientific Innovation (IJRSI), Volume IV, Issue VIS, June 2017 , ISSN 2321-2705

[7] K. Ravisankar, K. Sidhardha, Prabadevi B, "Analysis of Agricultural Data Using Big Data Analytics",Journal of Chemical and Pharmaceutical Sciences,July - September 2017,Volume 10 Issue 3,ISSN: 0974-2115.

[8] Ms.RuchitaThombare,Ms.ShreyaBhosale,Mr.Pras annaDhemey,Ms.AnaghaChaudhari, "Crop Yield Prediction Using Big Data Analytics",International Journal of Computer \& Mathematical Sciences IJCMS , Issue 11 November 2017, ISSN 2347 - 8527 Volume 6.

[9] S.VinilaKumari,Dr. P Bargavi,U. Subhashini, "Role of Big Data Analytics in Agriculture",Special Issue on Computational Science, Mathematics and Biology IJCSMESCSMB-16-March-2016 ISSN-2349-8439

[10] S.VinilaKumari,Dr. P Bargavi,U. Subhashini, "Role of Big Data Analytics in
Agriculture",Special Issue on Computational Science, Mathematics and Biology IJCSMESCSMB-16-March-2016 ISSN-2349-8439

[11] T.GiriBabu,Dr.G.AnjanBabu,"Big Data Analytics to Produce Big Results in the Agricultural Sector",International Journal of Advanced Research in Biology Engineering Science and Technology (IJARBEST),ISSN 2395-695X (Print), ISSN 2395-695X (Online),Vol. 2, Issue 3, March 2016

[12] Liping Di, "BIG DATA AND ITS APPLICATIONS IN AGROGEOINFORMATICS",IGARSS 2016,978-15090-3332-4/16

[13] Pal Ribarics, "Big Data and its impact on agriculture",2016, ISSN 2416-214.

[14] ShashiShekhar, Patrick Schnable, David LeBauer, Katherine Baylis and Kim VanderWaal, "Agriculture Big Data (AgBD) Challenges and Opportunities from Farm to Table: A Midwest Big Data Hub Community† Whitepaper, 2016

[15] ShoumitroChatterjee,DeveshKapur,

"Understanding Price Variation in Agricultural Commodities in India: MSP, Government Procurement, and Agriculture Markets",India Policy Forum, July 12-13, 2016.

[16] M. R. Bendre,R. C. Thool,V. R. Thool, "Big Data in Precision Agriculture: Weather Forecasting for Future Farmin",2015 1st International Conference on Next Generation Computing Technologies (NGCT-2015) Dehradun, India, 4-5 September 2015,978-14673-6809-4/15.

[17] Wu Fan, Chen Chong, GuoXiaoling, Yu Hua, WangJuyun, "Prediction of crop yield using big data",2015 8th International Symposium on Computational Intelligence and Design,978-14673-9587-8/15, (C) 2015 IEEE

[18] Jie Wang, Shuo Yang, Yuezhi Wang and Cheng Han, "The Crawling and Analysis of Agricultural Products Big Data based on Jsoup", 12th International Conference on Fuzzy Systems and Knowledge Discovery (FSKD),978-1-4673$7682-2 / 15$.

[19] Haoxiong Yang and Jing Hu,'Forecasting of Fresh Agricultural Products Demand Based on the ARIMA Model",Advance Journal of Food Science and Technology 5(7): 855-858, 2013,ISSN: 2042-4868; e-ISSN: 2042-4876, July $05,2017$. 